\title{
Survey of Heat-Stable, Major Somatic Antigens of Pseudomonas aeruginosa $\dagger$
}

\author{
PINGHUI V. LIU, ${ }^{1 *}$ HIDEKI MATSUMOTO, ${ }^{2}$ HIDEO KUSAMA, ${ }^{3}$ AND TOM BERGAN ${ }^{4}$ \\ Department of Microbiology, University of Louisville School of Medicine, Louisville, Kentucky 40292 ${ }^{1}$, \\ Department of Bacteriology, Faculty of Medicine, Shinshu University, Matsumoto, Japan ${ }^{2}$; Center for \\ Laboratories and Research, State of New York Department of Health, Albany, New York 12201 ${ }^{3}$; and \\ Department of Microbiology, University of Oslo, Oslo, Norway ${ }^{4}$
}

A survey of all serogrouping schemata for Pseudomonas aeruginosa was conducted in order to identify all of the heat-stable major somatic antigens. In addition to the 12 antigens described in the schema of Habs (Z. Hyg. 144:218-228, 1957), five antigens from other schemata were found to be distinct. A grouping schema comprising 17 groups based on these antigens is proposed as the international serogrouping schema for $\boldsymbol{P}$. aeruginos $a$. This schema is proposed as the backbone for future serotyping schemata that may include minor heat-stable antigens and heat-labile antigens. Several modifications of the schema are discussed. Variations of the schema can be adopted by individual laboratories without much confusion if the basic designations of the 17 antigens are retained.

Pseudomonas aeruginosa was isolated by Gessard (10) in 1882 as the cause of bluish green coloration of surgical dressings. Within 5 years of this discovery, the pathogenicity of this organism in experimental animals was established by Charrin (6). In 1896 Wasserman (37) differentiated antibodies directed against exotoxins and bactericidal antibodies directed against cells of $P$. aeruginosa, and in 1902 Achard et al. (1) described agglutination of $P$. aeruginosa by the serum of a man who was infected with the isolated agent. In 1903 Eisenberg (8) attempted to use such antisera to differentiate Bacillus pyocyaneus from Bacillus fluorescens. Similar work was reported by Jacobsthal (14) and Trommsdorf (32), who used a few strains of Pseudomonas species.

In 1926 Aoki (3) divided 50 strains of $P$. aeruginosa into 22 serotypes. This work was followed by the work of Kanzaki (15), Sandiford (30), Mayr-Harting (21), Christie (7), and van den Ende (33). The $P$. aeruginosa strains used by these workers were not preserved, and later investigators formed their own serotyping schemata as needed. The use of different serotyping schemata and the failure to preserve reference strains for future studies made it impossible to compare epidemiological data.

In 1957, Habs (11) described a serogrouping

† Members of the Subcommittee on Pseudomonadaceae who cooperated in this study: Joe A. Bass, A. E. Bunner, I. B. R. Duncan, John Farmer III, Y. Yuzuru Homma, B. Lanyi, E. J. L. Lowbury, Eugenia Meitert, S. Mikkelsen, M. T. Parker, T. L. Pitt, Muriel T. Rhodes (Secretary), R. Sakazaki, T. H. Siem, James Shewan (Chairman), and M. Veron. schema for $P$. aeruginosa that was based on 12 heat-stable somatic antigens. This schema has been used by most European workers in serological studies of $P$. aeruginosa from human sources. In 1960, Sandvik (31) described a serological study of $P$. aeruginosa strains from bovine infections and reported eight serogroups among these strains. Veron (35) found that only one of the serogroups of Sanvik (31) represented a new antigen that was not present in the schema of Habs (11) and proposed that group II of Sanvik (31) be added to the schema of Habs (11) as group 13.

In 1961, Verder and Evans (34) described an antigenic schema for $P$. aeruginosa that was based on both heat-stable and heat-labile antigens and divided the species into 10 serogroups on the basis of the heat-stable antigens. This schema has been used by many American investigators for clinical serotyping. Relationships between the serogroups in the schemata of Habs (11) and Verder and Evans (34) were clarified by the work of Muraschi et al. (26).

Serogrouping schemata for $P$. aeruginosa devised by Homma et al. $(12,13)$, Lanyi $(17)$, and Meitert and Meitert $(23,24)$ have been used by investigators in the respective countries of these workers. Relationships among serogroups in the schemata of Habs (11), Verder and Evans (34), and Lanyi (17) have been clarified by Matsumoto and Tazaki (20).

In 1969, Fisher et al. (9) published a schema for $P$. aeruginosa that was based on protective antigens, with the intention of developing a vaccine for clinical use. The serotypes of these authors were referred to as immunotypes, al- 
though there was no evidence that the antigens were different from the heat-stable somatic antigens which were used in other grouping schemata.

The proliferation of serogrouping schemata makes serological study of $\boldsymbol{P}$. aeruginosa very confusing. It would be desirable for investigators to adopt one serogrouping schema for this species so that published research data are comparable.

At a meeting of the Subcommittee on Pseudomonadaceae of the International Committee on Systematic Bacteriology held in Mexico City in 1970 , it was decided to evaluate the existing serogrouping schemata for $P$. aeruginosa and to recommend a schema acceptable to most, if not all, investigators. Many experts in this field were asked to provide reference strains for comparative studies, and the opinions of these experts were asked in the formulation of a single serogrouping schema. It was decided to use the data available in 1970 to select one schema as the basis for the selection of major antigens and to add to this any new antigens that may be found in the other schemata, so that the known major antigens would be represented in the proposed standardized schema.

\section{MATERIALS AND METHODS}

The typing schemata whose reference strains were available for comparative studies were those of Habs (11), Sandvick (31), Verders and Evans (34), Lanyi (17), Homma (12), Meitert (23), and Fisher et al. (9).

Antisera. The cultures were grown on Trypticase soy agar (BBL Microbiology Systems, Cockeysville, Md.) at $37^{\circ} \mathrm{C}$ for $18 \mathrm{~h}$. The cells were washed in saline and autoclaved at $121^{\circ} \mathrm{C}$ for $20 \mathrm{~min}$ to eliminate heatlabile antigens. The cells were then washed again with saline to eliminate surface slime, and the cultures were adjusted to cell densities that were equivalent to a MacFarland no. 3 nephelometer standard (about $3 \times$ $10^{9}$ to $4 \times 10^{9}$ cells per $\mathrm{ml}$ ). The standard procedure used for immunizing rabbits in the laboratory of one of us (P.V.L.) to produce agglutinating antisera is to inject intravenously $0.5,1.0$, and $3.0 \mathrm{ml}$ of a cell suspension on days 1,4 , and 7 . For some serotypes that are relatively poor antigens, it may be necessary to inject 10 times as many cells, as suggested by Mikkelsen (25). However, higher doses of antigens tend to produce more antibodies directed against cross-reacting minor antigens and, therefore, render the antisera less specific. High titers of antibodies directed against minor antigens also make the absorption of the sera more difficult.

The animals are bled about 1 week after the last injection. When the titers of antisera are not satisfactory, another injection $(5 \mathrm{ml})$ may be given, but this seldom improves the titer. When low titers of antisera are due to poor antigenicity of the antigen, immunization may be repeated with new animals; in such cases the first injection is an intramuscular injection of a cell suspension $\left(4 \times 10^{10}\right.$ cells per $\left.\mathrm{ml}\right)$ mixed with an equal volume of Freund adjuvant. Usually $2 \mathrm{ml}$ of such a mixture administered to animals at two to four injection sites serves the intended purpose. Subsequent intravenous injections are given at somewhat longer intervals (5 to 7 days).

The antisera obtained by total bleeding of animals may be preserved by adding either thimerosal (Merthiolate; Eli Lilly \& Co., Indianapolis, Ind.) to a final concentration of $1: 10,000$ or an equal volume of glycerol. The antisera that were used to evaluate serogrouping schemata by the international panel of experts were produced by Difco Laboratories, Detroit, Mich. and at least 10 rabbits were used for each serogroup. A pool of unabsorbed sera was used to evaluate the extent of cross-reactions in each serogroup.

Techniques for serological study. Basically two techniques can be used to serogroup clinical isolates. One is the slide agglutination technique, which is usually done at room temperature and depends on the immunoglobulin $\mathbf{M}$ contents of the sera. The other is the tube agglutination technique, which is usually done at a temperature of 37 to $50^{\circ} \mathrm{C}$, and the results usually measure the contents of immunoglobulin $\mathrm{G}$ in the sera. Both techniques have advantages as well as disadvantages, and the technique used depends on the worker who performs the experiments. The procedures used in the laboratory of one of us (P.V.L.) are as follows.

The cultures are grown on Trypticase soy agar (BBL) plates at $37^{\circ} \mathrm{C}$ for $18 \mathrm{~h}$. The cell masses are scraped off with cotton swabs and suspended in saline to densities of about $10^{10}$ cells per $\mathrm{ml}$ (i.e., three to four times as concentrated as the antigen used for immunizations). Live cell suspensions are used in the slide agglutination method by mixing 1 drop of cells and 1 drop of a 1:10 dilution of an antiserum. Agglutination is detected with either reflected or transmitted light within $30 \mathrm{~s}$. More than $90 \%$ of the clinical isolates of $P$. aeruginos $a$ can be grouped by the slide agglutination technique.

Strains of $P$. aeruginosa that cannot be grouped by the slide agglutination technique can usually be grouped by the tube agglutination method. Autoclaved cells are used instead of live cells, and cell suspensions similar to the suspension used for immunization are added to serial twofold dilutions of the antisera in saline. The tubes are incubated at either 37 or $50^{\circ} \mathrm{C}$, usually overnight. For most of the strains $37^{\circ} \mathrm{C}$ is satisfactory, but some strains agglutinate more readily at $50^{\circ} \mathrm{C}$ than at $37^{\circ} \mathrm{C}$.

When autoclaved cells of a $\boldsymbol{P}$. aeruginosa strain are not agglutinated by any of the 17 antisera used in the tube agglutination test, this strain contains a new $O$ antigen. However, it should be kept in mind that there is a heterogenous group of Pseudomonas species (not $P$. aeruginosa) that can be isolated from human specimens (2). Most of these organisms grow at $37^{\circ} \mathrm{C}$ but not at $42^{\circ} \mathrm{C}$; therefore, any Pseudomonas strain that is not agglutinated by the 17 antisera should be screened carefully for the maximum growth temperature, as well as other biological characteristics, in order to exclude other species of Pseudomonas.

\section{RESULTS}

Selection of a grouping schema. The reference strains of various grouping schemata mentioned above were used to identify major antigenic 
TABLE 1. Relationship between serogroups in various schemata ${ }^{a}$

\begin{tabular}{|c|c|c|c|c|c|c|c|c|c|}
\hline \multirow[b]{2}{*}{$\begin{array}{l}\text { Proposed } \\
\text { international } \\
\text { standard }\end{array}$} & \multicolumn{9}{|c|}{ Serogroup(s) in the schema of: } \\
\hline & $\begin{array}{l}\text { Habs } \\
(11)^{b}\end{array}$ & $\begin{array}{c}\text { Sandvik } \\
\text { (31) }\end{array}$ & $\begin{array}{l}\text { Veron } \\
\text { (35) }\end{array}$ & $\begin{array}{c}\text { Verder } \\
\text { and } \\
\text { Evans } \\
(34)\end{array}$ & $\begin{array}{l}\text { Lanyi } \\
\text { (17) }\end{array}$ & $\begin{array}{c}\text { Homma } \\
\text { (12) }\end{array}$ & $\begin{array}{l}\text { Fisher } \\
\text { et al. } \\
\text { (9) }\end{array}$ & $\begin{array}{l}\text { Meitert } \\
\text { and } \\
\text { Meitert } \\
\text { (24) }\end{array}$ & $\begin{array}{l}\text { Lanyi } \\
\text { and } \\
\text { Bergan } \\
(18)\end{array}$ \\
\hline 1 & 1 & VII & 1 & IV & 6 & 10 & 4 & 9 & 1 \\
\hline 2 & 2 & & 2 & I & 3 & 2 & 3 & 2 & $2 a, 2 c$ \\
\hline 3 & 3 & III & 3 & VI & 1 & 1 & & 5 & 3 \\
\hline 4 & 4 & IV & 4 & & 11 & 6 & & 8 & $4 a, 4 b$ \\
\hline 5 & 5 & & 5 & $\mathrm{X}$ & & 7 & 7 & 6 & $2 a, 2 d$ \\
\hline 6 & 6 & I & 6 & II & 4 & 8 & 1 & 1 & $6 \mathrm{a}$ \\
\hline 7 & 7 & & 7 & & & & & & $7 a, 7 b, 7 c$ \\
\hline 8 & 8 & VIII & 8 & VIII & 5 & 3 & 6 & 3 & $7 a, 7 b, 7 d$ \\
\hline 9 & 9 & V & 9 & IX & 9,10 & 4 & & & $9 \mathrm{a}$ \\
\hline 10 & 10 & & 10 & & 2 & 9 & 5 & 8 & $10 a, 10 b$ \\
\hline 11 & 11 & VI & 11 & III & 7 & 5 & 2 & & $11 a, 11 b$ \\
\hline 12 & 12 & & 12 & VII & 13 & & & 7 & 12 \\
\hline 13 & & II & 13 & & & 12 & & & $13 a, 13 b$ \\
\hline 14 & & & & V & & & & & $13 a, 13 c$ \\
\hline 15 & & & & & 12 & 11 & & & 15 \\
\hline 16 & & & & & 3 & 13 & & & $2 a, 2 b$ \\
\hline 17 & & & & & & & & 10 & 14 \\
\hline
\end{tabular}

${ }^{a}$ Only the major antigens of the reference strains are compared.

${ }^{b}$ The numbers in parentheses are reference numbers.

components of $P$. aeruginosa. It was not possible economically to produce antisera against all strains of all grouping schemata; therefore, one schema was selected as the major source of the antigens. Selections were made from previously published data $(20,26,35,36)$ and from opinions expressed by panel members. Most members agreed that the schema of Habs (11) should be

TABLE 2. Designations of the 17 reference strains, their origins, and their strain numbers

\begin{tabular}{|c|c|c|c|c|}
\hline \multirow{2}{*}{$\begin{array}{l}\text { IATS } \\
\text { no. }{ }^{a}\end{array}$} & \multirow{2}{*}{ Origin } & \multicolumn{3}{|c|}{ Strain } \\
\hline & & Designation & Source ${ }^{b}$ & ATCC no." \\
\hline 1 & Habs group 1 & 5833 & Veron & ATCC 33348 \\
\hline 2 & Habs group 2 & 5934 & Veron & ATCC 33349 \\
\hline 3 & Habs group 3 & 5935 & Veron & ATCC 33350 \\
\hline 4 & Habs group 4 & 5936 & Veron & ATCC 33351 \\
\hline 5 & Habs group 5 & 5937 & Veron & ATCC 33352 \\
\hline 6 & Habs group 6 & 5939 & Veron & ATCC 33354 \\
\hline 7 & Habs group 7 & 5938 & Veron & ATCC 33353 \\
\hline 8 & Habs group 8 & 5940 & Veron & ATCC 33355 \\
\hline 9 & Habs group 9 & 5941 & Veron & ATCC 33356 \\
\hline 10 & Habs group 10 & 5943 & Veron & ATCC 33357 \\
\hline 11 & Habs group 11 & 5944 & Veron & ATCC 33358 \\
\hline 12 & Habs group 12 & 5945 & Veron & ATCC 33359 \\
\hline 13 & Sandvik group II & 6092 & Veron & ATCC 33360 \\
\hline 14 & $\begin{array}{l}\text { Verder-Evans } \\
\text { group V }\end{array}$ & IM-1 & Verder & ATCC 33361 \\
\hline 15 & Lanyi group 12 & $\begin{array}{l}170022 \text { (original } \\
\text { designation, L83) }\end{array}$ & Lanyi & ATCC 33362 \\
\hline 16 & Lanyi group 3 & $\begin{array}{l}170003 \text { (original } \\
\text { designation, Ps11) }\end{array}$ & Lanyi & ATCC 33363 \\
\hline 17 & Meitert group 10 & & Meitert & ATCC 33364 \\
\hline
\end{tabular}

${ }^{a}$ IATS, International antigenic typing system (the proposed serogrouping schema based on the 17 heat-stable, major somatic antigens).

${ }^{b}$ Veron, M. Veron, Institut Pasteur, Paris, France; Verder, E. Verder, National Institutes of Health, Bethesda, Md.; Lanyi, B. Lanyi, State Institute of Hygiene, Budapest, Hungary; Meitert, E. Meitert, Academia de Stiinte Medicale, Bucarest, Roumania.

c ATCC, American Type Culture Collection. 
selected as the base schema for the following reasons.

Based on the data available in 1970 , the schema of Habs (11) had the largest number of serogroups. This schema is based on heat-stable antigens and did not have some of the ambiguities found in some of the other schemata. It was also the only schema that was well known in Europe and America, as well as in Asia. Adoption of this schema as the base schema should result in the smallest number of changes. The deadline of 1970 had to be adhered to because it was anticipated that new publications which describe more complete sets of antigens will continue to be made and it was not practical to change the base of selection every time such a publication appears. By adopting a base for the new international schema, we merely have to add new serogroups whenever they are found and described.

Additional antigens. The schema of Habs (11) contained 12 serogroups, each with a major specific antigen. Five additional major antigens were found in other schemata, and these antigens were added to those of Habs (11), resulting in a total of 17 major antigens. The relationships of these antigens to serogroups in other schemata are shown in Table 1. These 17 strains have been deposited in the American Type Culture Collection; their sources, origins, and strain numbers are listed in Table 2.

Group II of Sandvik (31) is known to be distinct from the serogroups of Habs (11) and is designated group $13(35)$. This proposal was accepted by most members of our panel. Group V of Verder and Evans (34), groups 12 and 3 of Lanyi (17), and group 10 of Meitert (23) were distinct and were added as groups 14, 15, 16, and 17 , respectively.

Evaluation of the antigens with a common pool of sera. Antisera against the 17 groups were produced by Difco Laboratories, which used at least 10 rabbits for each group. These sera were distributed to our panel members for evaluation. The purpose of this study was to evaluate the extent of cross-reactions due to minor antigens. We hoped that pools of sera produced by one source would eliminate the differences that are due to differences in antiserum production techniques.

Typical data obtained by using the tube dilution method in the laboratory of one of us (P.V.L.) are shown in Table 3. There were considerable differences in the degrees of crossreactions described by different laboratories. Cross-reactions were observed in groups 2 and 5 , groups 7 and 8 , groups 9 and 10 , and groups 13 and 14 . Some group 16 strains showed crossreactions with groups 2 and 5 and occasionally with other groups. However, it was possible to absorb each of the 17 antisera with appropriate cross-reacting strains so that only the major specific antibodies remained for serogrouping. The strains used in the absorption of each serum should be standardized because the specificities of the resulting sera undoubtedly depend on the strains selected for absorption. At present, there is no agreement on the selection of such absorbing strains.

The same antisera were used in slide agglutination tests, and very similar specificities and cross-reactivities were observed. The titers of the sera in slide agglutination tests ranged from 10 to 80 , and the sera were generally diluted to these ranges and tested with homologous strains before they were used in the routine tests. The results obtained by the slide agglutination technique may not be the same as those obtained when the tube agglutination method is used. Occasionally strains of $P$. aeruginosa exhibit multiple agglutinabilities. These strains may be agglutinated by the same serum on slides but exhibit different titers with different sera when they are tested with dilutions of these sera by the tube method.

Arrangement of serogroups. When the data presented above are used, it is possible to devise many different models of serogrouping schemata for $P$. aeruginosa, as follows.

(i) Model 1. The simplest schema recognizes only the most prominent antigen of each isolate and assigns each strain to 1 of the 17 groups. Difficultities are encountered with a small number of strains that agglutinate with more than one antiserum even when the sera are absorbed to reduce cross-reacting minor antibodies. These strains may be designated with multiple numbers or by the highest titers of agglutination with antisera.

(ii) Model 2. The second schema involves combining groups that tend to show cross-reactions; there are several possible models for these combinations.

(a) Model 2A. In model 2A groups 7 and 8 are combined, and there are 16 groups, which are designated $1,2,3,4,5,6,7 \& 8,9,10,11,12,13$, $14,15,16$, and 17 .

(b) Model 2B. Model 2B combines several groups that tend to cross-react, and there are 13 groups, which are designated $1,2 \& 5,3,4,6,7$, $\& 8,9 \& 10,11,12,13 \& 14,15,16$, and 17 . If desired, it is possible to divide the groups that are designated with two numbers into subtypes.

(c) Model 2C. Model 2C extends the practice of combining groups, and there are 11 groups, which are designated $1 \& 9 \& 10,2 \& 5 \& 16,3$, $4,6,7 \& 8,11,12,13 \& 14,15$ and 17 . If desired, it is possible to divide the groups with multiple numbers into subtypes.

(iii) Model 3. When determining serotypes 


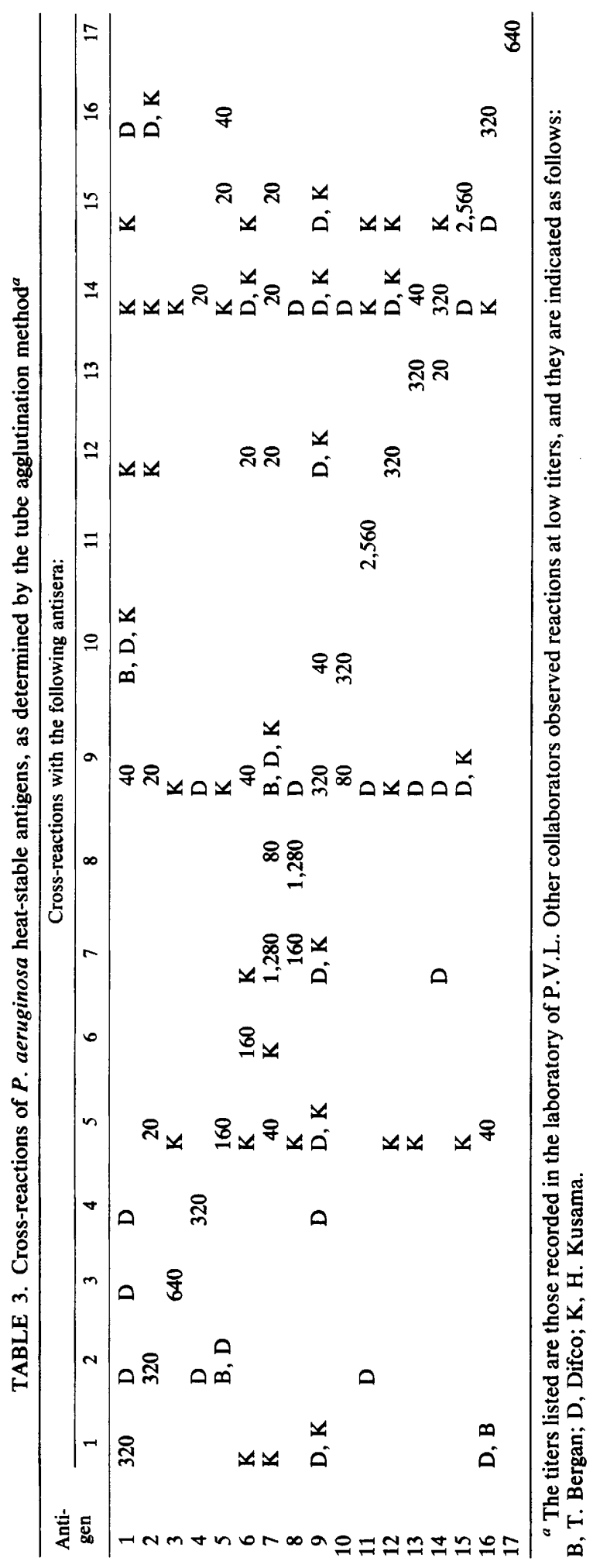


with the schemata described above, regardless of which model is selected, it is rather time consuming to check agglutination of an organism with all of the antisera. It has been suggested by several investigators that some of these groups may be combined to form pools of sera to facilitate serotype determinations. The idea is to divide all of the existing serogroups into three or four large pools for preliminary screening and then to determine definite types within each pool. The components of each of the pools would be selected on the basis of convenience of serum preparation, and each pool should contain groups that are difficult to separate, such as groups 2 and 5 and groups 7 and 8 , and groups that are easy to separate. Each pool should contain related serogroups as well as unrelated groups. (Such pools of sera should not be referred to as groups because the meaning of the term is different from the way it is used above, where group refers to serologically related organisms.)

Several combinations of pools have been suggested.

(a) Model 3A. Bunner suggested the following combinations based on the data obtained with Difco sera: pool A, comprising groups $1,3,9$, and 10; pool B, comprising groups 2, 5, 6, and 16; pool C, comprising groups $4,7,8$, and 11 ; and pool D, comprising groups $12,13,14,15$, and 17.

(b) Model 3B. Kusama (16) suggested the following combinations: pool I, comprising groups $1,4,11,12$, and 15 ; pool II, comprising groups $2,5,7,8$, and 16; and pool III, comprising groups 3, 6, 9, 10, 13, and 17 .

(c) Model 3C. Lanyi and Bergan (18) suggested the following combinations: pool I, comprising groups 3, 4, 6, 9, and 17; pool II, comprising groups $11,12,13$, and 15; pool III, comprising groups 2 and 5 and their various subgroups; and pool IV, comprising groups $1,7,8$, and 10 .

None of the systems described above has been widely accepted, and the choice of which to use should be left to each laboratory.

(iv) Model 4. A final remote possibility is to do away completely with any preformed serotyping schema and to merely describe the antigenic formula of each isolate, such as $0: 1,0: 2: 5$, or $0: 1: 9: 10$. The most prominent antigen should be listed first, and the minor antigens should follow. Heat-labile antigens, phage type, or pyocine type might be added to the formulas. However, it would be difficult to summarize such data.

Of the four models discussed above, model 1 appeared to be the most reasonable and the least objectionable for the following reasons. First, this model retains the format of the schema of $\mathrm{Hab}$, and, therefore, it is easy to compare pub- lished data. Second, the open-ended arrangement makes it easy to add new serogroups of $P$. aeruginosa when they are found. And third, strains of $P$. aeruginosa with combinations of antigens other than those listed above may be found, and it would be difficult to place these strains in preconceived combination groups. For example, many strains of $P$. aeruginosa that possess major antigen 16 show cross-reactions with group 2 and 5 antisera due to the presence of minor antigens. This is the basis for the suggestion by some investigators that group 16 should be combined with groups 2 and 5 . However, there are occasional strains having group 16 major antigen that show cross-reactions with sera other than group 2 and 5 sera. It does not seem appropriate to place these strains in a group that combines groups 2,5 , and 16; it is much more reasonable to place all strains with major antigen 16 in one group with the same designation and recognize that these strains can have minor antigens which cross-react with group 2 and 5 sera and some other sera.

Minor antigens and heat-labile antigens. Crossreactions between some of the groups, particularly cross-reactions between groups 2 and 5 , between groups 7 and 8 , and between groups 13 and 14, were due to minor antigens that may be present in considerable proportions. Obviously, these minor antigens have to be characterized in order to have a complete serotyping schema. However, interest in minor antigens varies from laboratory to laboratory, and studies of these antigens should be left to each laboratory according to its preferences and needs.

Heat-labile antigens are derived from flagella, pili, and other surface antigens $(4,28)$. Recognition and differentiation of heat-labile antigens are much more difficult than recognition and differentiation of heat-stable somatic antigens. Most investigators agree that studies of heatlabile antigens should be left to each worker, and attempts to standardize the nomenclature of these antigens are premature.

New somatic antigens. When a strain of $P$. aeruginosa is not agglutinated by any of the 17 antisera described above, it is possible that the organism possesses a new heat-stable antigen, and therefore, should form a new serogroup. However, it is also possible that the strain is not a $P$. aeruginosa strain. In the last 10 years it has become increasingly obvious that there are strains of other fluorescent pseudomonads which can be isolated from clinical sources that are not really $\boldsymbol{P}$. aeruginosa (2). Some of these organisms grow at $41^{\circ} \mathrm{C}$, but others do not. Some of them produce fluorescent pigments, but others are almost colorless. Most of these strains do not oxidize D-gluconate and also do not reduce nitrate to nitrogen gas. The groups of pseudomo- 
nads described by Ajello and Hoadley (2) as unidentified fluorescent Pseudomonas were actually a collection of heterogenous organisms that could be separated into four groups. Some of these organisms resembled Pseudomonas mendocina, but most of them were not established as distinct species. We should be careful not to include these organisms in the serogrouping schema for $P$. aeruginosa because such a practice would expand indefinitely the grouping for this species. Some recently published serogrouping schemata for $P$. aeruginosa include this type of organism (22).

We propose that whenever a new isolate of $P$. aeruginosa is found to be non-agglutinable with any of the 17 antisera described above, the organism should be checked for its ability to grow at $41^{\circ} \mathrm{C}$, its ability to oxidize gluconate, and its ability to reduce nitrate to nitrogen gas. The failure to exhibit any of these three characteristics should cast serious doubt that the strain is a $P$. aeruginosa strain.

\section{DISCUSSION}

The proposed grouping schema described above is essentially a proposal to use the 12 major anitgens in the schema of Habs (11) along with 5 additional heat-stable somatic antigens. It should be emphasized that this is not a proposal to adopt the schema of Habs (11) as such, but merely to utilize the antigens of the 12 reference strains in her schema. There are several minor antigens that appear in various combinations with these major antigens, and they will have to be characterized in the future. These minor antigens may provide the basis for subdivisions within groups.

We propose that arabic numerals be used to designate the major antigens, as well as the serogroups that are based on the major antigens. It is not likely that many more major antigens will be found among strains of $P$. aeruginosa, because 10 years of exhaustive surveys have resulted in the addition of only 5 antigens to the 12 described by Habs (11). Some of these antigens may be present in some strains in relatively minor proportions, and their recognition could result in differences of opinion regarding the formulation of a serotyping schema. Several models of these possible variations have been suggested, and experiences at different localities may dictate adoption of different models.

Most of the differences of opinion occurred regarding groups 7 and 8 , which cross-react considerably. Some panel members suggested combining these two groups into a single group, resulting in model $2 \mathrm{~A}$, whereas others wished to retain them as separate groups, thus retaining the format of model 1. Similar suggestions were made regarding the other cross-reacting combi- nations, such as groups 2 and 5 and groups 13 and 14. Adoption of these ideas would create models $2 \mathrm{~B}$ and $2 \mathrm{C}$. However, the use of these models would result in changes in group designations and thus some deviation from the original designations of Habs (11).

Furthermore, there are strains of $P$. aerugino$s a$ which possess different combinations of these antigens and, therefore, do not fit into any of the combined groups. This is why we favor model 1 as the basic schema. This schema is flexible enough so that laboratory workers can introduce their own combinations of groups or subtypes without much confusion, as long as the basic designation of each major antigen is not changed. In our laboratories, the system proposed above is referred to as the international antigenic typing schema to emphasize each antigenic component and not a fixed serotyping schema. This system includes all of the different models mentioned above, and some of these models have been used by Parker (27) and Lanyi and Bergan (18) in combination with some minor antigens to formulate locally suitable typing schemata. At present, we feel that establishment of a definite typing schema should be left to each laboratory to suit local needs. Some clinical workers may be satisfied to identify the basic 17 groups, whereas others may wish to combine these groups with minor antigens to define subtypes. Some workers may even combine these serotypes with the results of pyocine or bacteriophage typing (24).

A set of 17 unabsorbed sera (basically model 1) were made by Difco Laboratories for evaluation by panel members, and some of these sera were also made available to various clinical laboratories for actual serogrouping of clinical isolates. Unabsorbed sera were used to determine the extents of cross-reactions and thereby evaluate the necessity to resort to absorbed sera. Some of the results of clinical trials have been published $(5,16)$. These results may be summarized as follows.

When live $P$. aeruginosa strains were used in slide agglutination tests, 5 to $10 \%$ of the clinical isolates were nontypable. Practically all nontypable strains could be typed by using autoclaved cells in the tube agglutination test.

Some of the nontypable strains were not typical $\boldsymbol{P}$. aeruginosa strains. These organisms may be identical to the unidentified fluorescent pseudomonads described by Ajello and Hoadley (2), which are a collection of heterogenous pseudomonads that were isolated from clinical sources. Some of these organisms may share common antigens with typical $P$. aeruginosa strains, and it is difficult to draw a distinct line between these two groups.

Many of the typical $P$. aeruginosa strains that 
were not grouped when live cells were used in the slide agglutination test turned out to be polyagglutinable when the tube agglutination method was used; i.e., they were agglutinated by many antisera. These are the strains for which designation by listing all $O$ antigens is more appropriate than classification by serogroups.

Although the sera produced by Difco Laboratories were distributed without specific absorption of cross-reacting antibodies, cross-reactions in clinical trials were relatively minor, as shown by Brokopp et al. (5). Absorbed sera were used by Kusama (16) in slide agglutination tests, and a number of strains still showed multiple agglutination. A detailed antigenic analysis of such strains by the tube agglutination method should be performed.

Strains that are agglutinated with only one antiserum occasionally demonstrate antigenic differences due to additional antigens that are not detected by any of the 17 sera used. These additional, unknown antigens can be demonstrated only by producing antisera with these strains and performing cross-agglutination with these sera. Studies of these strains will undoubtedly lead to discovery of new antigens.

One more area in which standardization of nomenclature of antigens can be of value is the production of vaccines for prevention of infections. The relatively large number of major antigens makes it impractical to include all antigens in a vaccine. Practitioners of immunization in different localities may find it convenient to develop vaccines that contain only a few of the serogroups common in their localities, and universal acceptance of similar designations of these antigens should greatly reduce the confusion that could arise from the use of different typing schemata.

\section{LITERATURE CITED}

1. Achard, C., M. Loeper, and H. Grent. 1902. Seroreaction dans l'infection pyocyanique ches l'homme. C. R. Soc. Biol. 54:1274-1276.

2. Ajello, G. W., and A. W. Hoadley. 1976. Fluorescent pseudomonads capable of growth at $41^{\circ} \mathrm{C}$ but distinct from Pseudomonas aeruginosa. J. Clin. Microbiol. 4:443-449.

3. Aoki, K. 1926. Agglutinatorische Einteilung von Pyocyaneus-Bazillen welche bei verschiedenen Menschenerkrangungen nach gewiesen wurden. Zentralbl. Bakteriol. Parasitenkd. Infektionskr. Hyg. Abt. 1 Orig. 98:186-195.

4. Bradley, D. E., and T. L. Pitt. 1975. An immunological study of pili of Pseudomonas aeruginosa. J. Hyg. 74:419430.

5. Brokopp, C., D. Gomez-Lus, and J. J. Farmer III. 1977. Serological typing of Pseudomonas aeruginosa: use of commercial antisera and live antigens. J. Clin. Microbiol. 5:640-649.

6. Charrin, A. 1889. La maladie pyocyanique. G. Steinheil, Paris.

7. Christie, R. 1948. Observations on the biochemical and serological characteristics of Pseudomonas pyocyanea. Aust. J. Exp. Biol. Med. Sci. 26:425-437.

8. Eisenberg, P. 1903. Ueber die Anpassung der Bakterien an die Abwehrkraefte des infizierten Organismus. Zentralbl. Bakteriol. Parasitenkd. Infektionskr. Hyg. Abt. 1 Orig. 34:739-764.

9. Fisher, M. W., H. B. Devlin, and F. J. Gnabasik. 1969. New immunotype schema for Pseudomonas aeruginosa based on protective antigens. J. Bacteriol. 98:835-836.

10. Gessard, C. 1882 . Sur les colorations bleue et verte des linges a pansements. C. R. Acad. Sci. 94:536-538.

11. Habs, I. 1957. Untersuchungen ueber die O-Antigene von Pseudomonas aeruginosa. Z. Hyg. 144:218-228.

12. Homma, J. Y. 1976. A new antigenic schema and live-cell slide agglutination procedure for the infrasubspecific, serologic classification of Pseudomonas aeruginosa. Jpn. J. Exp. Med. 46:329-336.

13. Homma, J. Y., K. Sagehashi, and S. Hosoya. 1951. Serological types of Pseudomonas aeruginosa. Jpn. J. Exp. Med. 21:375-379.

14. Jacobstahl, E. 1912. Demonstration uber den Bac, pyocyaneus. Muench. Med. Wochenschr. 59:1247-1248.

15. Kanzaki, K. 1935. Immunisatorische Studien an pyozyaneus bazillen. I. Mitteilung; immunisatorische Einteilung von Pyozyaneus bazillen. Zentralbl. Bakteriol. Parsitenkd. Infektionskr. Hyg. Abt. 1 Orig. 133:89-101.

16. Kusama, H. 1978. Serological classification of Pseudomonas aeruginosa by a slide agglutination test. J. Clin. Microbiol. 8:181-188.

17. Lanyi, B. 1967. Serological properties of Pseudomonas aeruginosa. I. Group specific somatic antigens. Acta Microbiol. Acad. Sci. Hung. 13:295-318.

18. Lanyi, B., and T. Bergan. 1978. Serological characterization of Pseudomonas aeruginosa, p. 93-168. In T. Bergan and J. R. Norris (ed.), Methods in microbiology, vol. 10. Academic Press, Inc., New York.

19. Lanyi, B., A. W. Hoadley, and G. W. AJello. 1979. Heat stable somatic antigens of a group of unclassified fluorescent pseudomonas (UFP). Acta Microbiol. Acad. Sci. Hung. 26:111-120.

20. Matsumoto, H., and T. Tazaki. 1969. Relationships of Oantigens of Pseudomonas aeruginosa between Hungarian types of Lanyi and Habs type, or Verder and Evans types. Jpn. J. Microbiol. 13:209-211.

21. Mayr-Harting, A. 1948. The serology of Pseudomonas aeruginosa. J. Gen. Microbiol. 2:31-39.

22. Meitert, E., T. Meitert, F. Sima, C. Savulian, and A. Butoianu. 1978. New Pseudomonas aeruginosa serotypes following the individualization of new antigenic " $O$ " structures. Arch. Roum. Pathol. Exp. Microbiol. 37:161178.

23. Meitert, T. 1964. Contribution a l'etude de la structure antigenique des $B$. pyocyaniques (Pseudomonas aerugino$s a)$. Arch. Roum. Pathol. Exp. Microbiol. 3:679-688.

24. Meitert, T., and E. Meitert. 1966. Utilisation combinee du serotypage et de la lysotypie des souches de Pseudomonas aeruginosa on vue d'approfondir les investigations epidemiologiques. Arch. Roum. Pathol. Exp. Microbiol. 25:427-434.

25. Mikkelsen, O. S. 1968. Serotyping of Pseudomonas aeruginosa. I. Studies on the production of anti $O$ sera. Acta Pathol. Microbiol. Scand. 73:373-390.

26. Muraschi, T. G., D. M. Bolles, C. Moczulski, and M. Lindsay. 1966. Serologic types of Pseudomonas aerugino$s a$ based on heat-stable $O$ antigens; correlation of Habs (European) and Verder and Evans (North American) classification. J. Infect. Dis. 166:84-88.

27. Parker, M. T. 1976. Microbiology and epidemiology of Pseudomonas infections, p. 13-24. In I. B. R. Duncan, N. A. Hinton, and J. O. Godden (ed.), Diagnosis and management of gram-negative nosocomial disease. Eli Lilly Co. (Canada) Ltd., Publisher, Toronto.

28. Pitt, T. L., and D. E. Bradley. 1975. The antibody response to the flagella of Pseudomonas aeruginosa. J. Med. Microbiol. 8:97-106.

29. Pitt, T. L., and Y. J. Erdman. 1977. The specificity of agglutination reaction of Pseudomonas aeruginosa with $\mathrm{O}$ antisera. J. Med. Microbiol. 11:15-23. 
30. Sandiford, B. R. 1937. Observations in Pseudomonas pyocyanea. J. Pathol. Bacteriol. 44:567-572.

31. Sandvik, O. 1960. The serology of Pseudomonas aeruginosa from bovine udder infections. Acta Vet. Scand. 1:221-228.

32. Trommsdorf, R. 1916. Zur Kenntnis des Bakerium pyocyaneum und seiner Beziehungen zu den fluoreszierenden Bakterien. Zentralbl. Bakteriol. Parasitenkd. Infektionskr. Hyg. Abt. 1 Orig. 78:493-502.

33. van den Ende, M. 1952. Observations on the antigenic structure of Pseudomonas aeruginosa. J. Hyg. 50:405414.

34. Verder, E., and J. Evans. 1961. A proposed antigenic schema for the identification of strains of Pseudomonas aeruginosa. J. Infect. Dis. 109:183-193.

35. Veron, M. 1961. Sur l'agglutination des Pseudomonas aeruginosa; subdivision des groupes antigeniques $0: 2$ et O:5. Ann. Inst. Pasteur Paris 101:456-460.

36. Wahba, A. H. 1965. Hospital infection with Pseudomonas pyocyanea: an investigation by a combined pyocine and serological typing method. Br. Med. J. 1:86-89.

37. Wasserman, A. 1896. Experimentelle Untersuchungen ueber einige theoretische Punkte der Immunitaets lehre. Z. J. Hyg. Infektionskr. 22:263-313.

38. Wokatsch, R. 1964. Untersuchungen an Pseudomonas aeruginosa (Bact. pyocyaneus) aus verschiedenen Tierarten. Zentralbl. Bakteriol. Parsitenkd. Infektionskr. Hyg. Abt. 1 Orig. 192:468-476. 